\title{
ПРОБЛЕМА ПРОФЕССИОНАЛЬНОЙ ПОДГОТОВКИ УЧИТЕЛЕЙ НАЧАЛЬНЫХ КЛАССОВ К РЕАЛИЗАЦИИ ПРОГРАММ ДОПОЛНИТЕЛЬНОГО ОБРАЗОВАНИЯ
}

\section{Гусевская О.В.}

Цель. В статье выполнен краткий ретроспективный анализ развития внеурочной работы, выявляющий предпосылки становления современной системы дополнительного образования в России. Раскрыто авторское понимание целевого назначения дополнительного образования в современных сочиально-педагогических условиях. Обозначена актуальная необходимость в подготовке педагогических кадров, обладающих универсальными профессиональными компетенциями, т.е. специалистов, готовых к разработке и реализации программ дополнительного образования детей с использованием ресурсов научных организаций, организачий культуры и спорта (музеев, библиотек, виртуальных читальных залов, филармоний, театров, спортивных центров), медийных (использующих в качестве инструментов сервисы сети «Интернет», телевидения, радио, мультипликации) проектов.

Метод или методология проведения работы. Основу исследования составили методы анализа, обобщения, аналогии, систематизации, проектирования.

Результаты. Представлена авторская программа курса «Методика и технологии дополнительного образования» для студентовбакалавров педагогических вузов, обучающихся по направлению подготовки 44.03.05 Педагогическое образование (с двумя профилями подготовки) по профилю «Начальное образование - Дополнительное образование». Раскрываются ичель, задачи и содержание курса; представлена программа. Описана преемственность и вариативность содержания подготовки с иелью овладения системообра- 
зуюшими учебно-профессиональными действиями в меняющихся социокультурных условиях. Раскрыты технологические приемы, позволяющие повысить уровень овладения профессиональными компетенциями: решение учебно-профессиональных задач (кейсов); теоретическое моделирование и проектирование профессиональной деятельности.

Область применения результатов. Результаты могут быть применены в образовательном прочессе вуза с иелью подготовки специалистов, самостоятельно проектирующих и реализующчих программы дополнительного образования для обучающихся начальной школы в соответствии с требованиями ФГОС НОО.

Ключевые слова: начальное общее образование; младиий школьник; дополнительное образование; программа дополнительного образования; профессиональные компетенции; педагог дополнительного образования; программы дополнительного образования детей.

\section{THE ISSUE OF PRIMARY SCHOOL TEACHERS' PROFESSIONAL TRAINING TO IMPLEMENT PROGRAMS OF SUPPLEMENTARY EDUCATION}

\section{Gusevskaya O.V.}

Purpose. The article provides a brief overview of extracurricular activity origin and development that determines the formation prerequisites for the modern supplementary education system in Russia. The author's interpretation of supplementary education purposes in modern social and pedagogical environment is presented. The urgent need for the teachers' training with universal professional competencies is determined, i.e. the need for specialists ready to develop and implement programs of children's supplementary education using the resources of scientific, cultural and sports organizations (museums, libraries, virtual reading halls, philharmonic halls, theaters, sports centers), as well as media projects (involving the Internet, television, radio and animation). 
Method or work methodology. The study was based on the methods of analysis, generalization, analogy, systematization, designing process.

Results. The authorial program of Supplementary Education Methodology and Techniques course for the pedagogical university undergraduate students (field of study 44.03.05 Pedagogical Education (with two profiles of training), major profiles "Primary Education - Supplementary Education") is presented. The purpose, objectives and content of the course are disclosed, as well as the program is presented. The continuity and variability of the training content, aimed at mastering the system-forming educational and professional actions in changing sociocultural conditions, are described. Technological methods providing improvement of professional competences mastering are revealed: solution of educational and professional tasks (cases); theoretical modeling and design of professional activity.

Practical implications. The results can be applied in the educational process of the University in order to train specialists for independent design and implementation of additional education programs for primary school students in accordance with the FSES PGE requirements.

Keywords: primary general education; junior schoolchild; supplementary education; supplementary education program; professional competences; supplementary education teacher; supplementary education programs for children.

В связи с актуализацией в современном образовании роли внешкольного (дополнительного) образования многие учёные, педагоги, исследователи обратились к ретроспективе системы дополнительного образования детей и взрослых. Дополнительное образование в России имеет сложную и неоднозначную по своим задачам, функциям и организационной структуре историю развития. По данным ряда современных исследователей (И.В. Жгенти, А.В. Павлова, Н.Г. Тихомировой, Е.В. Смольникова и др.), источником дополнительного образования необходимо считать систему внешкольной работы, которая приобрела наиболее устойчивые формы к началу ХX века. Известно, что особый вклад в становление внеурочной систе- 
мы образования внесли К.Н. Вентцель, А.У. Зеленко, П.Ф. Лесгафт, С.Т. Шацкий, К.А. Фортунатов [5; 6; 9; 13; 16]. Следующие этапы развития внеурочного (дополнительного) образования тесным образом связаны с изменениями в политической и социальной ситуации страны. В сложный для страны послереволюционный период придавалось важное значение внешкольному образованию, и оно стало частью общей системы народного просвещения. В период 20-30 гг. ХХ в. закладывался фундамент становления внешкольных государственных учреждений, обладающих высоким воспитательным потенциалом. Именно в этот период происходит становление научно-методической базы дополнительного образования [9; 16]. В период 40-50 гг. XX века происходит стабилизация и укрупнение системы дополнительного образования, что обусловлено необходимостью систематизации процесса воспитания, жизненного самоопределения детей и их первичной профориентации в условиях социально-педагогической нестабильности послевоенного времени.

Активное развитие психолого-педагогических взглядов, становление идей индивидуально-личностного подхода переориентировали содержание программ дополнительного образования с учетом дифференциации интересов детей в 70-80-е годы. Данный подход актуализирован в современной концепции дополнительного образования детей [1].

Вместе с тем, уже начиная с 1986 г. детские организации переживают острый кризис $[5 ; 7 ; 8 ; 11]$, проявившийся в сокращении масштабов деятельности внешкольных учреждений и их количества. Кризис усугубился распадом пионерской и комсомольской организаций в 1991 г. Возникший вакуум в системе воспитания постепенно заполняется опять же за учреждений внешкольного образования. В 1992 г. с выходом нового закона «Об образовании» внешкольным учреждениям вернули статус образовательных учреждений и назвали учреждениями дополнительного образования детей (УДОД). В 1995 г. вышло «Типовое положение об учреждении дополнительного образования». Закон РФ «Об образовании» создал правовые предпосылки для перехода от унитарной, идеологизированной системы 
образования к системе вариативной, гуманистической, демократической. С 1992 г. отмечаются стабилизация (частичное восстановление) численности учреждений дополнительного образования, активизация их деятельности, что свидетельствует о выходе системы из кризиса [5]. По мнению многих исследователей, именно в этот период сформировались главные отличия этих учреждений от школы: свобода выбора деятельности, педагога, обучающей программы; возможность менять виды деятельности, коллектив, педагога; главным организующим началом стал не урок, а творчество в различных его проявлениях; между ребенком и педагогом сложились особые взаимоотношения сотрудничества и сотворчества; они позволяют ребенку найти свое место в жизни, получить допрофессиональную или начальную профессиональную подготовку [6].

Ретроспективный анализ развития внешкольного (дополнительного) образования позволяет нам констатировать, что данная форма образования сопровождает общество на протяжении длительного периода его развития и уверенно приобретает государственные масштабы даже в самые сложные периоды социально-политических преобразований в стране. Современный статус системы дополнительного образования детей предполагает становление её как неотъемлемой части общей системы образования России $[1 ; 2 ; 10 ; 15]$. По словам министра образования РФ О.Ю. Васильевой сейчас есть законные основания для реализации Программы дополнительного образования детей и в организациях дополнительного образования, и на базе школ, вузов, музеев и иных учреждений [12]. При этом, констатирует министр, очень важно, чтобы школа была укомплектована соответствующими кадрами с достаточным уровнем квалификации. Кроме того, она напомнила, что дополнительное образование имеет, по крайней мере, две цели. Во-первых, дополнительное образование, что следует уже из его названия, является дополнением к основному базовому плану школы. С одной стороны, углубляются и расширяются базовые знания, в опережающем графике осуществляется прохождение различных предметных курсов, с другой стороны, проводятся компенсирующие занятия для неуспевающих 
детей, и для детей с отставанием в развитии. Во-вторых, дополнительное образование выходит за рамки базового учебного курса, т.е. дети знакомятся с областями знаний, лежащих вне общеобразовательных программ, здесь находят свой интерес одаренные дети, а со старшеклассниками имеется возможность реализовать программы вузовской и допрофессиональной подготовки $[7 ; 12 ; 14]$.

В связи с этим, на государственном уровне обозначилась необходимость подготовки квалифицированных кадров, способных разрабатывать и реализовывать программы дополнительного образования с учётом современных требований общества, удовлетворяя запросы детей разных возрастов и их родителей, максимально используя ресурсы социокультурной среды.

Исходя из этого, для студентов 3-го курса Педагогического института Иркутского государственного университета (профиль «Начальное образование - Дополнительное образование») был разработан специальный учебный курс, который позволят освоить методику и технологии организации образовательного процесса в условиях дополнительного образования. Данный курс входит в состав обязательных дисциплин вариативной части профессионального цикла основной профессиональной образовательной программы [4]. Опору для изучения курса, составляют компетенции, приобретённые студентами в процессе изучения дисциплин в соответствии с учебным планом: «Педагогика», «Теория и методика воспитания (начальное образование)», «Психолого-педагогическая диагностика младшего школьника». Курс также ориентирован на процесс прохождения педагогической практики в качестве конкретной методологической основы для успешного осуществления всех компонентов педагогической деятельности в системе дополнительного образования и становления будущего специалиста.

Содержательную основу курса «Методика и технологии дополнительного образования» составляют положения «Федерального закона о дополнительном образовании», определяющие идеологию и нормативно-правовые основы профессиональной деятельности педагога дополнительного образования в современных социально- 
педагогических условиях. Системное освоение дисциплиной предполагает достижение следующих результатов. В личностной сфере студентов - способность к анализу и рефлексии своих личностных качеств и способностей для работы в структуре дополнительного образования; умение выстраивать взаимоотношения на основе сотрудничества с детьми в разновозрастных группах и их родителями; педагогическая мобильность и социальная активность. В учебнопрофессиональной сфере предполагается достижение результатов: готовность к самостоятельному проектированию программ дополнительного образования, подготовке их организационно-методического обеспечения; интеграция в условия сетевого взаимодействия дополнительного образования и организаций различного типа (библиотеки, музеи, театры и пр.) [4].

Курс рассчитан на 18 лекционных, 36 практических и 54 часа для самостоятельной работы студентов. Содержательная структура дисциплины по выбору разбита на четыре раздела. В рамках освоения первого раздела студенты анализируют генезис системы дополнительного образования; определяют роль дополнительного образования в развитии, воспитании и социализации детей; изучают наследие выдающихся педагогов-создателей первых детских клубов и объединений: А.У. Зеленко, С.Т. Шацкого, А.А. Фортунатова. Знакомятся и анализируют современные подходы, разработанные педагогами, работающими над теорией и методикой дополнительного образования: А.Г. Асмоловым, А.К. Брудновым, В.А. Горским, А.В. Золотаревой, Е.Б. Евладовой, М.Б. Коваль, Н.Г. Крыловой, Л.Г. Логиновой, Н.А. Морозовой, Г.Н. Поповой, А.Б. Фоминой, М.Ю. Чековым, А.И. Щетинской и др.

Важным для становления профессиональных компетенций в области теории и практики дополнительного образования является освоение второго учебного раздела. Учебный процесс предполагает выполнение студентами заданий на учебное проектирование, решение web-квестов, работу с кейсами. Например, задание на учебное проектирование: «Разработать миссию учреждения дополнительного образования с учётом следующих требований: 
- социальные запросы, потребности, интересы общества, ожидания детей, связанные с учреждениями дополнительного образования;

- социальные, демографические, этнокультурные, экономические особенности региона; нормативные требования, предъявляемые органами управления образованием к учреждениям подобного типа;

- сложившаяся система, структура и особенности образовательного процесса учреждения;

- особенности контингента детей и родителей, их потребности, интересы и запросы;

- уровень профессиональной компетентности, мотивация педагогического коллектива;

- материальная база и финансовые возможности учреждения дополнительного образования детей» [4]. Выполнение задания требует от студентов на основе изучения потребностей заказчика образовательных услуг (детей и родителей), анализ тенденций развития организации, оценку ресурсной базы на этой основе конкретизацию целей и задач учреждения дополнительного образования. Подобные задания выводят студентов на активный уровень усвоения. Результаты проектирования студенты представляют в виде презентации и публичной защиты.

При работе с кейсами студенты-бакалавры имеют возможность в первом приближении познакомиться с основными положениями по разработке программ дополнительного образования и методикой их реализации. Они изучают типы и виды программ, требования к их разработке; осваивают этапы работы над образовательной программой. Кейс представляет собой учебно-методический комплекс образовательной программы дополнительного образования: программу учебных занятий, методические рекомендации, инструкции по организации образовательного процесса; схемы, карты, таблицы, фотографии, репродукции, макеты, модели, используемые в процессе обучения; компьютерное программное обеспечение; описание обучающих игр, тренингов, упражнений, задач, практических 
заданий; средства контроля, вопросы, задания, тесты (педагогические и психологические); информация о пособиях, энциклопедиях, словарях-справочниках, периодических изданиях, электронных носителях информации, используемых в программе; аудио-теле-видеоматериалы. Студенты получают установку перед работой с кейсом: выполнить экспертирование образовательной программы в соответствии с экспертным листом оценивания образовательной программы дополнительного образования, в котором отражены основные критерии и показатели эффективности. Задание групповое, перед работой в группе из 5-ти человек необходимо распределить роли: методист, психолог отдела, специалисты по профилю программы, научные консультанты, экспертная группа методического совета. Критерии оценки выполненного задания: решение задачи правильное, демонстрирует применение аналитического и творческого подходов, знание учебного материала по теме; продемонстрированы умения работы в ситуации неоднозначности и неопределенности; решение задачи представлено на контроль в срок. Подобные задания наиболее продуктивно и осознанно позволяют осваивать студентам приёмы проектирования образовательных программ.

Не менее важным является освоение учебного содержания третьего раздела. Его содержание предполагает освоение учащимися технологии организации и проведения учебного занятия дополнительного образования. Студенты изучают специфику форм, структуры, содержания, принципы организации учебного занятия дополнительного образования. Овладевают приёмами отбора педагогических технологий с учётом целей и задач занятия. Осваивают современные образовательные технологии: технология проведения учебного занятия, построенного в соответствии с теорией общего развития (Л.В. Занков), технология проведения учебного занятия в системе дифференцированного обучения (И. Унт), технология проведения учебного занятия в соответствии с теорией проблемного обучения (М.И. Махмутов, И.Я. Лернер), организация занятия на основе групповой технологии, технология построения учебного занятия в соответствии с теорией педагогики сотрудничества, техно- 
логическая цепочка группового творческого воспитательного дела (И.П. Волков, И.П. Иванов), технология проведения учебного занятия-игры и другие.

Учебное содержание четвёртого раздела программы ориентирует студентов на требования к профессиональной компетентности педагога дополнительного образования. Будущие учителя знакомятся со структурой и содержанием компетентности педагога дополнительного образования; изучают проблемное поле становления профессиональной компетентности педагога в современных условиях развития дополнительного образования («Профессиональный стандарт педагога дополнительного образования», «Единый квалификационный справочник должностей руководителей, специалистов и служащих» и пр.). Кроме того, учебное содержание дисциплины позволяет студентам сориентироваться в видах и формах повышения профессиональнопедагогической квалификации педагогов дополнительного образования: методические объединения, творческие лаборатории, кафедры, мастер-классы, школы передового опыта, стажёрские площадки и пр., тем самым выстроить вектор своего профессионального развития.

Формой аттестации по дисциплине «Методика и технологии дополнительного образования» является зачет с оценкой. Зачет включает два этапа - «теоретический» - выявление знаний по изученной дисциплине; «практический» - самостоятельное проектирование учебного занятия дополнительного образования по любой из направленностей (на выбор студентов) с последующей защитой.

Успешное освоение дисциплины формирует у студентов способность проектировать дополнительные общеобразовательные программы в соответствии с требованиями нормативных документов, образовательных стандартов и особенностями образовательной среды; анализировать, оценивать и использовать опыт образовательных организаций по разработке развивающей образовательной среды; проектировать и оценивать достижение личностных, метапредметных и предметных результатов обучающихся; готовность включаться в педагогическое сопровождение процессов социализации и профессионального самоопределения обучающихся, подготовки 
их к сознательному выбору профессии; способность включаться во взаимодействие с родителями, коллегами, социальными партнерами, заинтересованными в обеспечении качества процесса общего дополнительного образования школьников.

Таким образом, интегрированный характер построения учебного содержания, осваиваемого студентами на теоретических и практических занятиях по дисциплине «Методика и технологии дополнительного образования», использование специальных образовательных технологий, позволяют формировать у них знания о специфике дополнительного образования, его роли в личностном становлении и предпрофессиональном самоопределении младших школьников, формирует способность использовать систематизированные теоретические и практические знания гуманитарных, социальных, психолого-педагогических наук при решении профессиональных задач в структуре дополнительного образования.

\section{Список литературы}

1. «Концепция развития дополнительного образования детей», Распоряжение Правительства РФ от 04.09.2014 N 1726-p http://legalacts. ru/doc/rasporjazhenie-pravitelstva-rf-ot-04092014-n-1726-r/ (дата обращения: 12.04.18).

2. Асмолов А.Г. Дополнительное образование как зона ближайшего развития образования в России: от традиционной педагогики к педагогике развития// Внешкольник. 1997. № 9. С. 6-9.

3. Березина В.А. Воспитание и дополнительное образование обучающихся в контексте нового Федерального закона «Об образовании в Российской Федерации» // Внешкольник. 2013. №1. С. 6-10.

4. Гусевская О.В. Рабочая программа дисциплины «Методика и технологии дополнительного образования» [Электронный ресурс] URL: https://isu.ru/filearchive/edu_files/B1.V.OD.16.1Metodikaitekhnologiid op.obr_959.pdf (дата обращения: 22.02.18).

5. Жгенти И.В. Дополнительное образование детей в России: прошлое, настоящее, будущее (историко-педагогический обзор) // Педагогика искусства. № 4, 2014. С. 349-354. 
6. Золотарева А.В. Дополнительное образование детей: Теория и методика социально-педагогической деятельности. Ярославль: Академия развития, 2004. 304 с.

7. Иванюшина В.А., Александров Д.А. Социализация через неформальное образование: внеклассная деятельность российских школьников // Вопросы образования. 2014. № 3. С. 174-197.

8. Косарецкий С.Г., Куприянов Б.В., Филиппова Д.С. Особенности участия детей в дополнительном образовании, обусловленные различиями в культурно-образовательном и имущественном статусе семей и месте проживания // Вопросы образования. 2016. № 1. С. 168-190.

9. Новые исследования по истории советской педагогики и школы: сборник научных трудов № 155. Ярославль, ЯГПУ: Ростовская типография им. М.И. Калинина, 1976. 122 с.

10. Павлов А.В. Дополнительное образование - продолжение или альтернатива? // Материалы Международной конференции и VII международного научно-практического семинара «Многоязычие и межкультурная коммуникация: вызовы XXI века». Прага, 2013. С. 12-22.

11. Попова И.П. Образование в жизненных стратегиях женщин с детьми // Женщина в российском обществе. 2010. № 1. С. 51-61.

12. Российское образование. Федеральный портал [Электронный реcypc] URL:http://www.edu.ru (дата обращения: 12.02.18).

13. Смольников Е.В. Становление и развитие системы дополнительного образования детей в отечественной педагогике: историко-педагогический анализ: дис...канд. пед. наук. Ульяновск, 2006. 229 с.

14. Тихомирова Н.Г. История развития системы дополнительного образования детей в России // Образовательная панорама. 2014. № 1. C. $113-118$.

15. Федеральный закон от 29 декабря 2012 г. № 273-ФЗ «Закон об образовании в Российской Федерации» http://sch1213s.mskobr.ru/ files/federal_nyj_zakon_ot_29_12_2012_n_273-fz_ob_obrazovanii_v_ rossijskoj_federaii.pdf (дата обращения: 20.02.18).

16. Халилулина Ю.Н. Дополнительное образование детей как социально-педагогическое явление // Вестник Московского государственного университета культуры и искусств. 2006. № 3-2. С. 123-127. 


\section{References}

1. «Kontseptsiya razvitiya dopolnitel'nogo obrazovaniya detey», Rasporyazhenie Pravitel'stva RF ot 04.09.2014 N 1726-r ["The concept of development of supplementary education for children", Order of the Government of the Russian Federation dated 04.09.2014, no 1726-p]. http://legalacts.ru/doc/rasporjazhenie-pravitelstva-rf-ot-04092014-n-1726-r/ (date of access: 12.04.18)

2. Asmolov A.G. Dopolnitel'noe obrazovanie kak zona blizhajshego razvitija obrazovanija v Rossii: ot tradicionnoj pedagogiki k pedagogike razvitija [Supplementary education as a zone of the nearest development of education in Russia: from traditional pedagogy to development pedagogy]. Vneshkol'nik. 1997, no. 9: 6-9.

3. Berezina V.A. Vospitanie i dopolnitel'noe obrazovanie obuchajushhihsja v kontekste novogo Federal'nogo zakona «Ob obrazovanii v Rossijskoj Federacii» [Education and supplementary education of students in the context of the new Federal Law "On Education in the Russian Federation"]. Vneshkol'nik. 2013, no. 1: 6-10.

4. Gusevskaya O.V. Rabochaya programma distsipliny «Metodika i tekhnologii dopolnitel'nogo obrazovaniya» [The work program of the discipline "Methodology and technologies of supplementary education"]. https://isu.ru/filearchive/edu_files/B1.V.OD.16.1Metodikaitekhnologiidop.obr_959.pdf (date of access: 22.02.18).

5. Zhgenti I.V. Dopolnitel'noe obrazovanie detej v Rossii: proshloe, nastojashhee, budushhee (istoriko-pedagogicheskij obzor) [Children's supplementary education in Russia: past, present, future (historical and pedagogical review)] Pedagogika iskusstva. 2014, no. 4: 349-354.

6. Zolotareva A.V. Dopolnitel'noe obrazovanie detej: Teorija i metodika social 'no-pedagogicheskoj dejatel'nosti [Children's supplementary education: Theory and methodology of social and pedagogical activity]. Akademiya razvitiya. Yaroslavl', 2004. 304 p.

7. Ivanyushina V.A., Aleksandrov D.A. Socializacija cherez neformal'noe obrazovanie: vneklassnaja dejatel'nost' rossijskih shkol'nikov [Social engagement through non-formal education: extracurricular activities of Russian schoolchildren]. Voprosy obrazovaniya. 2014, no. 3: 174-197. 
8. Kosaretskiy S.G., Kupriyanov B.V., Filippova D.S. Osobennosti uchastija detej v dopolnitel'nom obrazovanii, obuslovlennye razlichijami v kul'turno-obrazovatel'nom i imushhestvennom statuse semej i meste prozhivanija [Specific features of children's participation in additional education due to differences in the cultural, educational and property status of families and place of residence]. Voprosy obrazovaniya. 2016, no. 1: 168-190.

9. Novye issledovaniya po istorii sovetskoy pedagogiki i shkoly: sbornik nauchnykh trudov no.155 [New research on the history of Soviet pedagogy and school: a collection of scientific papers no. 155]. Yaroslavl', YaGPU: Rostovskaya tipografiya im. M.I. Kalinina, 1976. 122 p.

10. Pavlov A.V. Dopolnitel'noe obrazovanie - prodolzhenie ili al'ternativa? [Supplementary education - an extension or alternative?]. Materialy Mezhdunarodnoy konferentsii i VII mezhdunarodnogo nauchno-prakticheskogo seminara «Mnogoyazychie i mezhkul 'turnaya kommunikatsiya: vyzovy XXI veka» [Materials of the International Conference and the VII International Scientific and Practical Seminar "Multilingualism and Intercultural Communication: Challenges of the 21st Century"]. Praga, 2013: 12-22.

11. Popova I.P. Obrazovanie v zhiznennyh strategijah zhenshhin s det'mi [Education in the life strategies of women with children]. Zhenshchina v rossiyskom obshchestve. 2010. no. 1: 51-61.

12. Rossiyskoe obrazovanie. Federal'nyy portal [Russian education. Federal online resource]. http://www.edu.ru (date of access: 12.02.18).

13. Smol'nikov E.V. Stanovlenie i razvitie sistemy dopolnitel'nogo obrazovaniya detey $v$ otechestvennoy pedagogike: istoriko-pedagogicheskiy analiz [Formation and development of the system of supplementary education of children in the national pedagogy: historical and pedagogical analysis]. Ul'yanovsk, 2006. 229 p.

14. Tihomirova N.G. Istoriya razvitiya sistemy dopolnitel'nogo obrazovaniya detej v Rossii [History of the development of the system of supplementary education for children in Russia]. Obrazovatel'naya panorama. 2014. № 1: 113-118.

15.Federal'nyy zakon ot 29 dekabrya 2012 g. № 273-FZ «Zakon ob obrazovanii v Rossiyskoy Federatsii» [Federal Law no. 273-FZ dated Decem- 
ber 29, 2012 "The Law on Education in the Russian Federation"]. http:// sch1213s.mskobr.ru/files/federal_nyj_zakon_ot_29_12_2012_n_273fz_ob_obrazovanii_v_rossijskoj_federaii.pdf(date of access: 20.02.18). 16. Khalilulina Yu.N. Dopolnitel'noe obrazovanie detej kak social'no-pedagogicheskoe javlenie [Children's supplemenatry education as a socio-pedagogical phenomenon]. Vestnik Moskovskogo gosudarstvennogo universiteta kul'tury i iskusstv. 2006. no. 3-2: 123-127.

\section{ДАННЫЕ ОБ АВТОРЕ}

Гусевская Ольга Валерьяновна, доцент кафедры психологии и педагогики начального образования

Иркутский государственный университет

ул. Карла Маркса, 1, г. Иркутск, Иркутская область, 664015, Российская Федераиия

gusevsk58@gmail.ru

\section{DATA ABOUT THE AUTHOR}

Gusevskaya Olga Valer'yanovna, Candidate of Pedagogical Sciences, Associate Professor

Irkutsk State University, Pedagogical Institute

1, Karla Marksa Str., Irkutsk, Irkutskaya oblast, 664015, Russian Federation

gusevsk58@gmail.ru

SPIN-code: 3271-3325

ORCID: 0000-0001-6544-7741 